\title{
Research trends in electrochemical technology for water and wastewater treatment
}

\author{
Tianlong Zheng ${ }^{1} \cdot$ Juan Wang $^{1} \cdot$ Qunhui Wang $^{1} \cdot$ Huimin Meng ${ }^{2}$. \\ Lihong Wang ${ }^{1,3}$
}

Received: 27 May 2014/ Accepted: 11 March 2015/Published online: 26 March 2015

(c) The Author(s) 2015. This article is published with open access at Springerlink.com

\begin{abstract}
It is difficult to completely degrade wastewater containing refractory pollutants without secondary pollution by biological treatment, as well as physical-chemical process. Therefore, electrochemical technology has attracted much attention for its environmental compatibility, high removal efficiency, and potential cost effectiveness, especially on the industrial wastewater treatment. An effective bibliometric analysis based on the Science Citation Index Core Collection database was conducted to evaluate electrochemical technology for water and wastewater treatment related research from 1994 to 2013. The amount of publications significantly increased in the last two decades. Journal of the Electrochemical Society published the most articles in this field with a top h-index of 90, taking
\end{abstract}

Qunhui Wang

wangqh59@sina.com

Tianlong Zheng

skytal_03@sina.com

Juan Wang

pizi0909@163.com

Huimin Meng

ecm@ustb.edu.cn

Lihong Wang

wanglihong-48@126.com

1 Department of Environmental Engineering, University of Science and Technology Beijing, 30 Xueyuan Road, Haidian District, Beijing 100083, China

2 Laboratory for Corrosion-Erosion and Surface Technology, Corrosion and Protection Center, University of Science and Technology Beijing, 30 Xueyuan Road, Haidian District, Beijing 100083, China

3 Department of Architectural Engineering, Handan Polytechnic College, 141 Zhuhe Road, Handan 056001, Hebei, China
$5.8 \%$ of all, followed by Electrochimica Acta and Journal of Electroanalytical Chemistry. The researchers focused on categories of chemistry, electrochemistry, and materials science. China and Chinese Academy of Sciences were the most productive country and institution, respectively, while the USA, with the most international collaborative articles and highest h-index of 130, was the major collaborator with 15 other countries in top 20 most productive countries. Moreover, based on the analysis of author keywords, title, abstract, and 'KeyWords Plus', a new method named "word cluster analysis" was successfully applied to trace the research hotspot. Nowadays, researchers mainly focused on novel anodic electrode, especially on its physiochemical and electrochemical properties.

Keywords Scientometrics - Web of science core collection - Electrochemical technology $\cdot$ Research trends . Water and wastewater treatment

\section{Introduction}

With the world's rapid population growth, the water pollution has become a serious global problem for the indiscriminate discharge of wastewater. Therefore, more efficient and cost-saving wastewater treatment technologies are vital to satisfy the ever-increasing requirements of human beings. Generally, wastewater treatment is carried out by the conventional wastewater treatment process (Grady Jr et al. 2011; Afzal et al. 2011), such as, physicalchemical methods and biological methods. However, it is difficult to degrade the complex refractory organic pollutant in the wastewater by biological methods. In addition, physical-chemical methods are not always effective due to the unreacted chemicals and sludge treatment (Feng et al. 
2003; Afzal et al. 2011). Nowadays, electrochemical technology, which was applied to water and wastewater treatment, has attracted great attention for its environmental compatibility, high removal efficiency, and potential cost effectiveness. Electrochemical technology including electrocoagulation, electrodeposition, electrooxidation, electrodisinfection, electrofenton, electroflotation, and electrosorption, may be one of the most effective technologies. Among them, electrodisinfection process (Ghernaout and Ghernaout 2010), which is extremely popular in recent years, has great potential to eliminate and disinfect drinking water, swimming pool water and industrial cooling water. Compared with electrodisinfection, electrofenton was widely applied in the treatment of wastewater containing toxic and nonbiodegradable materials (Jiang and Zhang 2007). In addition, electroflotation technology was used in the elimination of flocs and suspended sludge of wastewater (Chen et al. 2002; Ge et al. 2004), while electrosorption technology effectively removed polar molecules or ions from wastewater (Huang and Su 2010). However, electrocoagulation, electrodeposition and electrooxidation still were the uppermost electrochemical technologies during water and wastewater treatment in the history. Electrooxidation, which was extensively investigated since the late 1970s (Mayeda et al. 1972; Nilsson et al. 1973), had been used worldwide in various refractory wastewater treatments, such as textile wastewater (Andrade et al. 2007), olive mill wastewater (Un et al. 2008), distillery industry wastewater (Piya-Areetham et al. 2006), dye-containing wastewater (Valero et al. 2010), brown-colored molasses wastewater (Canizares et al. 2008), and coking wastewater (Zhu et al. 2009). Recently, researchers have paid more concern on anodic material of electrodes and its electrochemical performance and degradation mechanism (Marselli et al. 2003; Chen 2004; Chang et al. 2009). The common electrodes (Gao et al. 1994; Chen 2004; Martinez-Huitle and Ferro 2006; Anglada et al. 2009; Zhu et al. 2009), such as, graphite, $\mathrm{Pt}, \mathrm{PbO}_{2}, \mathrm{SnO}_{2}$, Ti/Pt, Ti/SnO $2, \mathrm{Ti} / \mathrm{PbO}_{2}, \mathrm{Ti} / \mathrm{RuO}_{2}-$ $\mathrm{TiO}_{2}, \quad \mathrm{Ti} / \mathrm{IrO}_{2}-\mathrm{TiO}_{2}, \quad \mathrm{Ti} / \mathrm{IrO}_{2}-\mathrm{RuO}_{2}-\mathrm{TiO}_{2}$, boron-doped diamond electrode (BDD), Titanium-based boron-doped diamond electrode (BDD/Ti) are usually found in the wastewater treatment field. Moreover, novel anodic material will be the future frontier of electrochemical technology for water and wastewater treatment related research.

Bibliometrics, which gained insight into the development trends of various research fields through a quantitative analysis and statistics, firstly introduced by Pritchard in 1969 (Pritchard 1969). Science Citation Index Expanded $^{\mathrm{TM}}$, accessed via Web of Science ${ }^{\mathrm{TM}}$ Core Collection, was the most important and frequently used source database for an overview of scientific production. Bibliometric methods have been widely applied to assess the scientific outputs of various fields, especially on environmental concerns and energy utilization frontier, such as drinking water (Hu et al. 2010), nitrate removal (Huang et al. 2012), sediment (Niu et al. 2014), solid waste (Fu et al. 2010), volatile organic compounds (Zhang et al. 2010a), and materials of lithiumbased batteries (Wagner et al. 2013). In addition, research patterns including journals, categories, countries, and institutes, as well as the international cooperation had been broadly applied (Fu et al. 2010, 2014; Niu et al. 2014; Tan et al. 2014). Moreover, h-index, namely the number $h$ of publications with at least $\mathrm{h}$ citations, which was introduced by Hirsch in 2005 (2005), had become a valid indicator on scientific achievement (Hirsch 2007; Ciriminna and Pagliaro 2013; Tan et al. 2014). In addition, the analysis of author keywords, title, abstract, and 'KeyWords Plus' in different periods also had been used to evaluate the research trend in recent years (Xie et al. 2008; Fu et al. 2010, 2014; Wang et al. 2013).

In this study, a comprehensive bibliometric analysis was used to trace and obtain the global trend on electrochemical technology for water and wastewater treatment research from 1994 to 2013. Document types, languages, categories, journals, countries/territories, institutions, and h-index were analyzed to dissect the publication pattern. Further, research tendency and hotspot including the distribution of author keywords, title, abstract, and 'KeyWords Plus' in different periods, and hot issues were also applied. Besides, an effective method named "word cluster analysis" (Mao et al. 2010) was applied to trace the hotspot of related research field in previous work. The results could provide a basis for comprehensive understanding of global development and serve as a potential guide for future direction of electrochemical technology for water and wastewater treatment related research.

\section{Data sources and methodology}

One common method of bibliometric research used to trace publications was using the SCI of the Institute for Scientific Information (ISI). The original information sources were based on the database of the Web of Science Core Collection and the Journal Citation Report (JCR) of 2012 by Thomson Reuters, where we extracted information about scientific output on 7 April, 2014. According to Journal Citation Reports (JCR) of 2012, it indexes 8471 journals with citation references across 176 scientific disciplines. Since 1991, abstract information has been included in the SCI. The topic search can trace the related information in the title, abstract, and keywords at one time.

(electrochemi* or electro-chemi*) and [wastewater or (waste water) or waste-water or water] were used as a 
search phrase to search topics in SCI for the period from 1994 to 2013. Aspects referring to document type, language, output, subject category, journal, country, institute, source title, abstract keyword, and h-index were all analyzed by Microsoft Excel 2010. The contribution of different countries and institutes were estimated by the location of the affiliation of at least one author of the published papers. Articles that originated from Hong Kong were included under the China heading for analysis. Articles that originated from England, Scotland, Northern Ireland, and Wales were grouped under the UK heading. "Internationally collaborative publication" was designated to those articles that were coauthored by researchers from more than one country, where "independent type" was assigned if the researchers' addresses were from the same country. The term "single institute publication" was assigned if the researchers' addresses were from the same institute. The term "inter-institutionally collaborative publication" was assigned if the authors were from different institutes. h-index was defined by the $\mathrm{h}$ of $\mathrm{Np}$ papers having at least $\mathrm{h}$ citations each and the other (Np-h) papers have $\leq \mathrm{h}$ citations each. The reported IF of each journal was obtained from the 2012 JCR Science Edition.

\section{Results and discussion}

\section{Publication pattern}

\section{Document type and language of publication}

The 29,144 publications related to the electrochemical technology for water and wastewater treatment research identified by the ISI between 1994 and 2013 included 8 document types. Articles were the dominant document type comprising $90 \%$ or 26,330 of the total production. The remaining publications were proceedings papers (1557), review (1048), meeting abstract (77), letter (57), editorial material (25), notes (23), book chapter (15), correction (9), and reprint (3). On average, there were 17 articles per proceedings papers and 25 articles per review.

As articles (26330) were the dominant type of publications, these were analyzed in the following study. For language analysis, 25,551 articles (97\%) were published in English, followed by Chinese (439), Japanese (88), German (43), French (39), Portuguese (36), Spanish (32), Rumanian (31), Russian (21), Polish (21), SerboCroatian (9), Hungarian (6), Czech (4), Korean (4), Italian (3), and only one article each in Turkish, Ukrainian, and Malay, respectively. Obviously, English was by far the dominant language in the journals listed in SCI.

\section{Characteristics of publication outputs}

As there are no abstracts in the publications of the SCI before 1991, (electrochemi* or electro-chemi*) and (wastewater or (waste water) or waste-water or water) were used as a search phrase in the title only to obtain a general long-term trend of electrochemical technology for water and wastewater treatment. The earliest research Web of Science ${ }^{\mathrm{TM}}$ Core Collection on electrochemical technology for water and wastewater treatment related was published in 1911. Figure 1 shows that the amount of electrochemical technology for water and wastewater treatment research has slowly grown in the long period from 1911 to 1990 . The amount of publications goes up significantly in 1991 and rockets during the period since 2013. The electrochemical technology for water and wastewater treatment research has become a hot topic worldwide, because of high rate increase of related literatures and human beings urgent necessary for energy and environment.

During the study period, the cumulative number of articles grew from 461 in 1994 to 26,330 in 2013. A power model and an exponential model described the relationship between the annual cumulative number of articles and the year published for the two periods from 1994 to 2003 and 2003 to 2013, respectively (Fig. 2). A significant correlation between the number of articles and the year was observed with a high coefficient of determination $\left(R^{2}>0.998\right)$. Both the power and the exponential curve fitting indicated that there was a high growth rate for annual articles. The power and exponential fitting curves for research of electrochemical technology for water and wastewater treatment were found to be: $C_{1}=438.17 Y^{1.19}$ $\left(R^{2}=0.999\right)$ and $C_{2}=\exp (0.13 Y+7.55)\left(R^{2}=0.9989\right)$, respectively, where $C$ is the cumulative number of articles

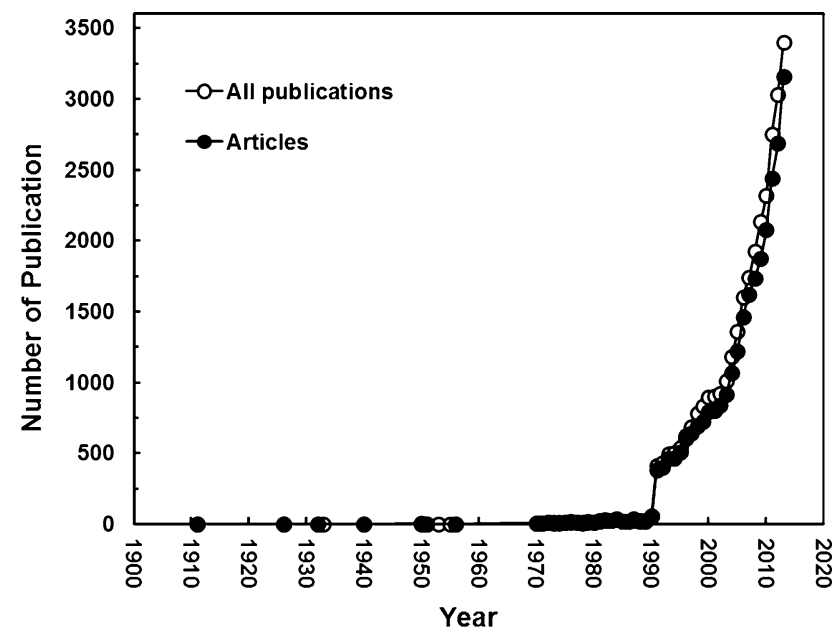

Fig. 1 Number of SCI publications on electrochemical technology for water and wastewater treatment research during the last 110 years 


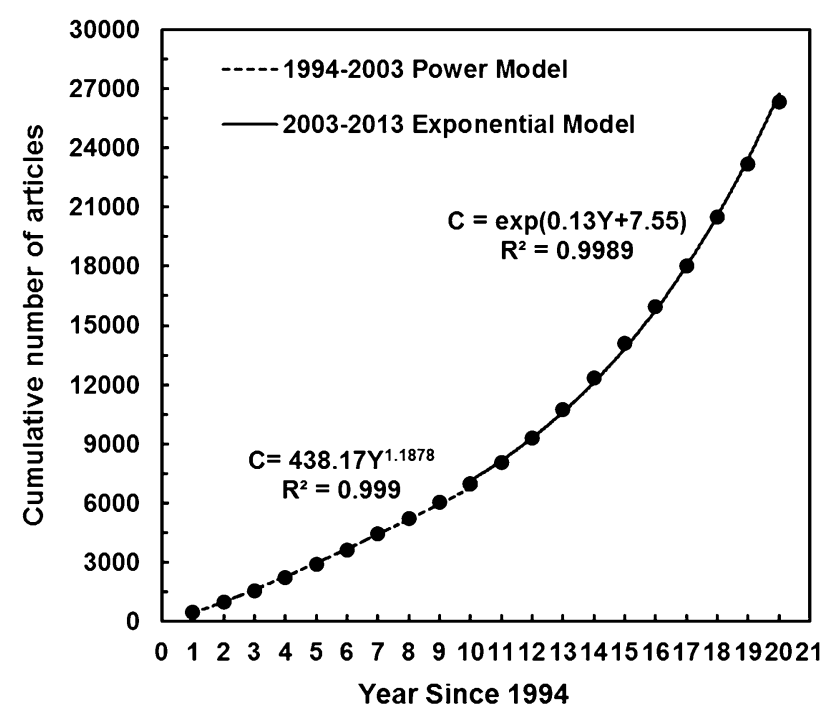

Fig. 2 The relationship between cumulative number of publications and published year

and $Y$ is the number of years since 1994. Based on the exponential model during 2003-2013, the number of articles in 2018 (6406) is predicted to be twice more than that in 2013 (3160).

The number of authors per article increased from 3.3 in 1994 to 4.8 in 2013 and the increasement was $47 \%$, with a similar increase in the number of references cited per article and the number of institutions per article, and the corresponding increasement was 43 and $33.5 \%$. The average article length fluctuated slightly, with an overall average length of 7.9 pages. The number of countries per article was stable at 1.2 countries. Of the 26,330 articles, $183(0.7 \%)$ articles did not include abstracts. Of the 183 articles without abstracts, $71(38.8 \%)$ articles were published during 2010-2013. Similar to the analysis of articles abstract, $24(0.1 \%)$ of 26,330 articles did not cite references, and the most common number of references per article was 27 and 30 which were found in 751 articles $(2.9 \%)$. Of the 24 articles without references, 9 (38\%) articles were published in 1994 and 1995.

Articles (26,330) were analyzed, including 985 (3.7\%) articles without reprint author information. The most frequent number of authors was three, accounting for 5829 articles (22.1\%). Two to five authors accounted for 19811 articles $(75.2 \%)$ and 848 articles $(3.2 \%)$ had one author, and the maximum number of authors per article was 31 [which was published on corrosion science named "effect of the marine environment on reinforced concrete durability in Iberoamerican countries: DURACON project/ CYTED" (Trocónis De Rincón et al. 2007)]. The 26,330 articles contained a total of 208,848 pages, and the maximum number of pages per article was 98 [which was a review of the research literature published in 2010 dealing with physico-chemical processes used for water and wastewater treatment (Afzal et al. 2011)], and the minimum number was one. Six to eight pages $(12,212 ; 46.4 \%)$ were the most frequent number of pages (Table 1).

\section{Output in subject categories and journals}

Articles $(26,330)$ were published in 1790 journals in 106 subject categories in SCI. Among these journals, 1432 $(80 \%)$ journals contained less than 10 articles. Top 20 most productive journals (TP $>240$ ) and their ISI category of journals, and the position of the journal in its category, IF in 2012, h-index and Journal Country are shown in Table 2.

Both IF and h-index were used to evaluate the articles in a journal. There was a high concentration of electrochemical technology for water and wastewater treatment research publications in these top journals. Table 2 shows the top 20 most productive journals, accounting for appropriately $38 \%$ of the total articles. Journal of the Electrochemical Society with the highest h-index of 90, published the most articles with 1540 articles (5.8\%), followed by Electrochimica Acta (1334; $5.1 \%)$, Journal of Electroanalytical Chemistry (801; $3.0 \%$ ), and Journal of Power Sources $(554 ; 2.1 \%)$.The percentage of the top productive journal was not high, which indicates the breadth of article distribution as well as the broad interest in electrochemical technology for water and wastewater treatment research from various research angles. This phenomenon also appears in other environment related research areas, such as Water research $(4.2 \%)$ in drinking water (Fu et al. 2013), Water research $(2.2 \%)$ in nitrate removal research (Huang et al. 2012), and Marine Pollution Bulletin (8.4\%) in estuary pollution research (Sun et al. 2012a). Journal of the Electrochemical Society, which remained one of the most-highly cited journals in electrochemistry since 1902, ranked on top in the category of Materials Science, Coatings and Films (17) with an impact factor of 2.588 . It is worth mentioning that International Journal of Electrochemical Science from Serbia with a high IF (3.729) in 2011 and the least h-index (13) in 2012 according to JCR, which published tenth most articles with 116 (1.5\%), was suppressed by JCR 2012 because of anomalous citation. The relationship between h-index, IF and the rank order of the 20 most productive journals revealed extremely different trend. For example, Journal of Applied Electrochemistry ranked 8 th in the top 20 of most productive journals, while IF (1.836) and h-index (39) ranked 20th and 15th, respectively; on the contrary, Journal of the American Chemical Society ranked 18th in top 20 of most productive journals, when IF (10.677) and h-index (66) ranked 1st and 3rd. 
Table 1 Characteristics by year of publication outputs from 1994 to 2013

\begin{tabular}{|c|c|c|c|c|c|c|c|c|c|c|c|}
\hline Year & $\mathrm{TP}$ & $\mathrm{AU}$ & AU/TP & NR & NR/TP & PG & PG/TP & NI & NI/TP & $\mathrm{NC}$ & NC/TP \\
\hline 1994 & 461 & 1509 & 3.3 & 12,931 & 28.0 & 3641 & 7.9 & 637 & 1.4 & 506 & 1.1 \\
\hline 1995 & 510 & 1681 & 3.3 & 14,613 & 28.7 & 4127 & 8.1 & 721 & 1.4 & 585 & 1.1 \\
\hline 1996 & 601 & 2064 & 3.4 & 16,493 & 27.4 & 4664 & 7.8 & 846 & 1.4 & 689 & 1.1 \\
\hline 1997 & 644 & 2225 & 3.5 & 17,973 & 27.9 & 5187 & 8.1 & 939 & 1.5 & 741 & 1.2 \\
\hline 1998 & 690 & 2504 & 3.6 & 19,412 & 28.1 & 5701 & 8.3 & 1062 & 1.5 & 802 & 1.2 \\
\hline 1999 & 726 & 2681 & 3.7 & 19,551 & 26.9 & 5865 & 8.1 & 1057 & 1.5 & 830 & 1.1 \\
\hline 2000 & 796 & 2938 & 3.7 & 22,583 & 28.4 & 6337 & 8.0 & 1246 & 1.6 & 946 & 1.2 \\
\hline 2001 & 801 & 3042 & 3.8 & 22,052 & 27.5 & 6308 & 7.9 & 1256 & 1.6 & 966 & 1.2 \\
\hline 2002 & 838 & 3250 & 3.9 & 24,562 & 29.3 & 6803 & 8.1 & 1349 & 1.6 & 999 & 1.2 \\
\hline 2003 & 917 & 3450 & 3.8 & 25,854 & 28.2 & 7264 & 7.9 & 1457 & 1.6 & 1098 & 1.2 \\
\hline 2004 & 1070 & 4231 & 4.0 & 32,765 & 30.6 & 8614 & 8.1 & 1711 & 1.6 & 1268 & 1.2 \\
\hline 2005 & 1221 & 4944 & 4.0 & 37,608 & 30.8 & 9684 & 7.9 & 1986 & 1.6 & 1475 & 1.2 \\
\hline 2006 & 1462 & 5950 & 4.1 & 44,592 & 30.5 & 11,633 & 8.0 & 2426 & 1.7 & 1765 & 1.2 \\
\hline 2007 & 1620 & 6759 & 4.2 & 51,964 & 32.1 & 12,587 & 7.8 & 2646 & 1.6 & 1927 & 1.2 \\
\hline 2008 & 1733 & 7349 & 4.2 & 57,299 & 33.1 & 13,201 & 7.6 & 2964 & 1.7 & 2091 & 1.2 \\
\hline 2009 & 1875 & 8062 & 4.3 & 63,351 & 33.8 & 14,305 & 7.6 & 3230 & 1.7 & 2248 & 1.2 \\
\hline 2010 & 2080 & 9203 & 4.4 & 76,224 & 36.6 & 15,802 & 7.6 & 3588 & 1.7 & 2522 & 1.2 \\
\hline 2011 & 2440 & 11,123 & 4.6 & 89,474 & 36.7 & 19,180 & 7.9 & 4307 & 1.8 & 2995 & 1.2 \\
\hline 2012 & 2685 & 12,574 & 4.7 & 104,263 & 38.8 & 21,901 & 8.2 & 4758 & 1.8 & 3295 & 1.2 \\
\hline 2013 & 3160 & 15,213 & 4.8 & 126,336 & 40.0 & 26,044 & 8.2 & 5831 & 1.8 & 3973 & 1.3 \\
\hline Total & 26,330 & 110,752 & & 879,900 & & 208,848 & & 44,017 & & 31,721 & \\
\hline Average & & & 4.0 & & 31.2 & & 7.9 & & 1.6 & & 1.2 \\
\hline
\end{tabular}

$T P$ number of articles, $A U$ number of authors, $N R$ cited reference count, $P G$ page count, $N I$ institution count, $N C$ country count, $A U / T P, N R / P$, $P G / T P, N I / T P, N C / T P$ average number of authors, pages, references, institutions, countries, per articles

This result might attribute to the large number of subject categories in our current research. Among the top 20 journals, ten journals are from USA, four from Netherlands, three from the UK (England), two from Switzerland, one from Germany and Serbia, which revealed the dominated status of developed countries in journal country.

Due to the assignment of journals to multiple subject categories, electrochemical technology for water and wastewater treatment research covered 106 Web of Science categories. As illustrated in Fig. 3, based on the continuous increase in the number of articles of each category, electrochemical technology for water and wastewater treatment research in the six subject categories had steadily increased especially at the beginning of the 21 st century. The most common subject category was chemistry, followed distantly by other categories. The other two relatively popular subject categories belonged to the second echelon were electrochemistry and materials science, which had kept a sound momentum. Moreover, the research trend in these two fields was the hotspots in the current study.
Of the 1790 journals publishing the 26,330 articles, 705 (39.4\%) journals contained 1 article, 272 (15.2\%) journals contained two articles, $145(8.1 \%)$ journals contained 3 articles and $82(4.6 \%)$ journals contained four articles. Approximately, $5159(19.6 \%)$ articles were published in 6 core journals, and for comparison, the trends in the six journals with the greatest number of articles are shown in Fig. 4. The number of articles in Journal of the Electrochemical Society and Electrochimica Acta had slowly increased from 1993 to 1998, and significantly went up in general since 1998, and then fluctuated in recent years. The other four journals concluding Journal of Electroanalytical Chemistry, Journal of Power Sources, International Journal of Hydrogen Energy, and Electroanalysis, which revealed the same growth trend in the research period, rose undulate from 1993 to 2011 and showed a promising development since 2011 .

\section{Publication performances: institutes and countries}

The contribution of different countries and territories were estimated by the affiliation of at least one author to the 







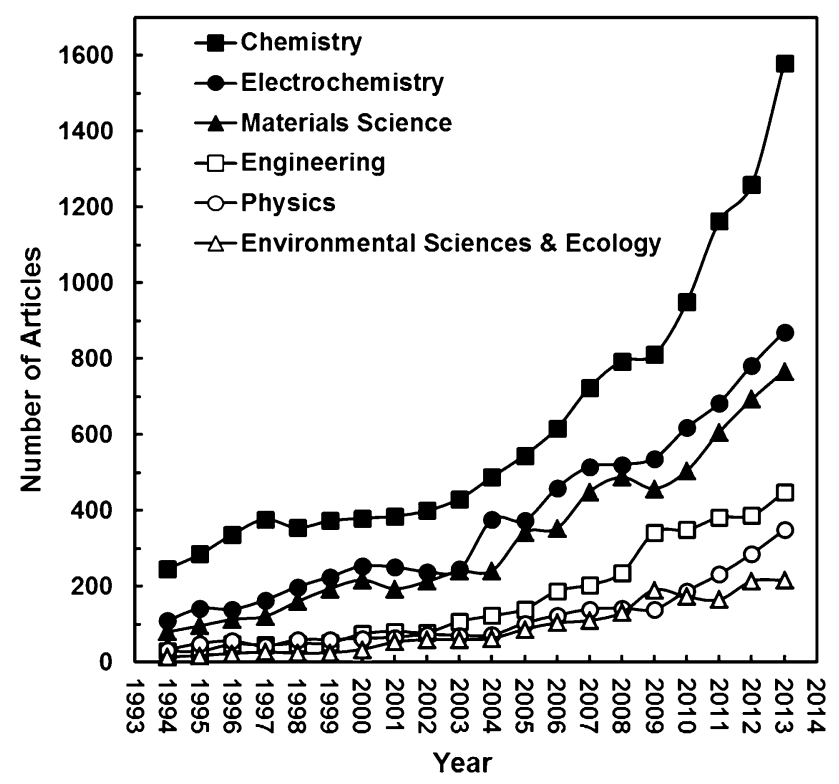

Fig. 3 The growth trends of the top 6 subject categories

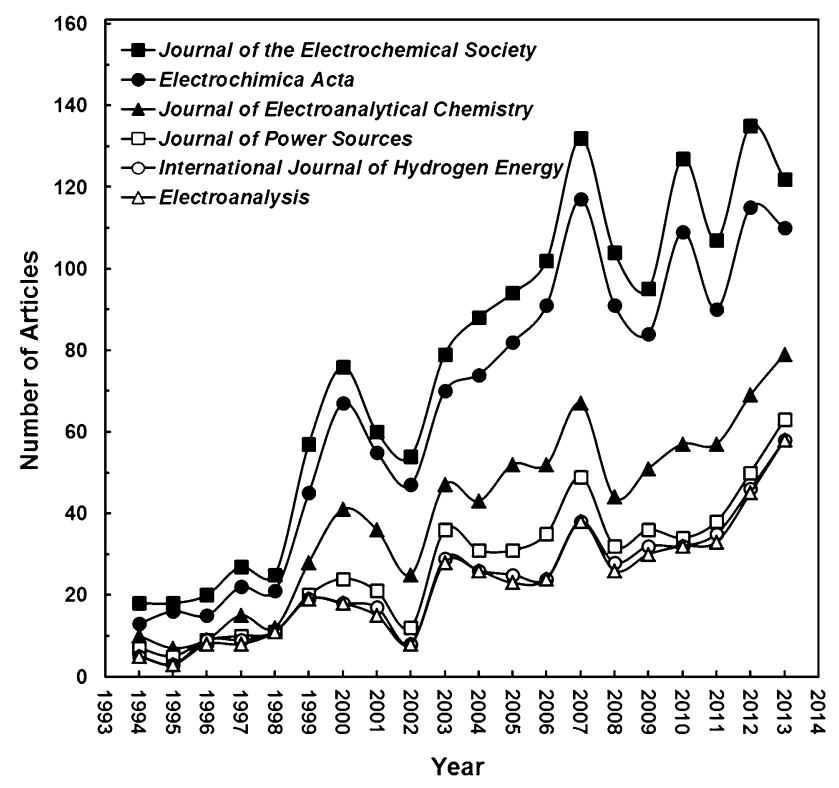

Fig. 4 The growth trends of the top 6 journals

publications. Moreover, the publication, number of the countries and territories could reveal the research performance in the related field. Excluding 34 articles without any author address information on the ISI Web of Science, of the 26,296 articles with author address information, published from 1994 to 2013 were analyses. This covered 118 countries/territories, of which 21,556 (82.0\%) were independent articles covering 100 countries/territories and $4740(18.0 \%)$ were international collaborative articles covering 114 countries/territories. Table 3 shows the top 20 most productive countries for total articles. Number of total, single-country, internationally collaborated articles, the percentage of single-country articles in total articles, the percentage of international collaborative articles in total articles, and the h-index of countries/territories were exhibited in Table 3. The number of countries involved in electrochemical technology for water and wastewater treatment research increased rapidly. Nine European countries, six Asian countries/territories, four American countries, and one Oceania country were ranked in the top 20 productive countries of articles. The top 20 most productive countries included $80.7 \%$ of the total number of articles. The seven major industrialized countries (G7: Canada, France, Germany, Italy, Japan, the UK, and USA), ranked in the top 11, had $40.7 \%$ over the investigation period. The result indicated that the developed countries hold a dominant position in electrochemical technology for water and wastewater treatment research as this pattern has occurred in most scientific fields (Zhang et al. 2010b; Fu et al. 2010). Moreover, some developing countries, such as BRIC (China, India, Brazil, and Russia) were also listed as productive countries with 7441 or $23.2 \%$ of total articles.

China dominated, ranking first in total articles (4939), independent articles (4231), first authored articles (4640) and corresponding authored articles (4561), and had 2nd h-index of 83. However, China was ranked 19th of the 20 countries on percentage of collaboration with outside authors, while the UK ranked 9th in the number of articles, that had the highest proportion of collaborative articles to total articles. Simultaneously, the UK was ranked 1st with nearly $64 \%$ of international collaborative articles in its total articles. The proportions of internationally collaborated articles to the total outputs of these 20 countries showed significant disparity. Yet, USA with the highest h-index of 130 not only predominantly completed the most collaborative articles (1286), but also was the major collaborator of 15 other countries (Table 3), which indicated that USA still had unparalleled strength and leadership in the scientific research. In addition, although single-country articles still dominated in the electrochemical technology for water and wastewater treatment research, based on intensifying academic exchanges in the electrochemical technology for water and wastewater treatment study area, international collaboration was popular worldwide in recent years, which had also been a general trend in other fields (Fu et al. 2010; Niu et al. 2014). In the current study, the relationship between h-index and the rank order of the 20 most productive countries of articles revealed almost similar trends.

USA had the highest h-index of 130 and six countries had an h-index of 70-85. It is notable that Switzerland was ranked 19th in the number of articles but unexpectedly 10th in h-index and India was ranked 7th in the number of articles but only 11 th in h-index. Figure 5 showed that China continuously ranked 1 st in the number of articles per year since 
Table 3 Top 20 most productive countries of articles during 1994-2013

\begin{tabular}{|c|c|c|c|c|c|c|c|c|}
\hline \multirow[t]{2}{*}{ Country/territories } & \multirow[t]{2}{*}{$\mathrm{TP}$} & \multirow[t]{2}{*}{$R(\%)$} & \multicolumn{2}{|c|}{ Single-Country } & \multicolumn{3}{|c|}{ Internationally-collaborated } & \multirow{2}{*}{ h-index $[R]$} \\
\hline & & & SP & $\%$ & $\mathrm{CA}$ & $\%[R]$ & $\mathrm{MC}[P]$ & \\
\hline China & 4939 & $1(18.8)$ & 4231 & 85.67 & 708 & $14.33(19)$ & USA (204) & $83(2)$ \\
\hline USA & 4481 & $2(17.0)$ & 3195 & 71.30 & 1286 & $28.70(12)$ & China (204) & $130(1)$ \\
\hline Japan & 2180 & $3(8.3)$ & 1745 & 80.05 & 435 & $19.95(16)$ & China (115) & $73(3)$ \\
\hline France & 1663 & $4(6.3)$ & 927 & 55.74 & 736 & $44.26(4)$ & USA (77) & $71(5)$ \\
\hline Germany & 1392 & $5(5.3)$ & 715 & 51.36 & 677 & $48.64(2)$ & USA (104) & $73(3)$ \\
\hline Spain & 1309 & $6(5.0)$ & 831 & 63.48 & 478 & $36.52(7)$ & USA (58) & $71(5)$ \\
\hline India & 1267 & $7(4.8)$ & 1004 & 79.24 & 263 & $20.76(15)$ & USA (38) & $51(11)$ \\
\hline UK & 1141 & $8(4.3)$ & 621 & 54.43 & 520 & 45.57 (3) & USA (74) & $64(8)$ \\
\hline South Korea & 1082 & $9(4.1)$ & 787 & 72.74 & 295 & $27.26(13)$ & USA (132) & $50(12)$ \\
\hline Italy & 937 & $10(3.6)$ & 587 & 62.65 & 350 & $37.35(6)$ & USA (64) & $70(7)$ \\
\hline Canada & 879 & $11(3.3)$ & 610 & 69.40 & 269 & $30.6(11)$ & USA (79) & $63(9)$ \\
\hline Brazil & 700 & $12(2.7)$ & 537 & 76.71 & 163 & 23.29 (14) & USA (27) & $42(14)$ \\
\hline Taiwan & 659 & $13(2.5)$ & 562 & 85.28 & 97 & $14.72(18)$ & USA (33) & $41(15)$ \\
\hline Iran & 564 & $14(2.1)$ & 505 & 89.54 & 59 & $10.46(20)$ & USA (13) & $38(17)$ \\
\hline Russia & 535 & $15(2.0)$ & 352 & 65.79 & 183 & $34.21(10)$ & Germany (34) & $32(19)$ \\
\hline Australia & 518 & $16(2.0)$ & 296 & 57.14 & 222 & $42.86(5)$ & China (61) & $46(13)$ \\
\hline Poland & 487 & 17 (1.9) & 319 & 65.50 & 168 & $34.5(9)$ & USA (32) & $34(18)$ \\
\hline Turkey & 437 & $18(1.7)$ & 350 & 80.09 & 87 & $19.91(17)$ & USA (26) & $40(16)$ \\
\hline Switzerland & 393 & $19(1.5)$ & 185 & 47.07 & 208 & $52.93(1)$ & Germany (42) & $62(10)$ \\
\hline Mexico & 361 & $20(1.4)$ & 235 & 65.10 & 126 & 34.9 (8) & USA (42) & $30(20)$ \\
\hline
\end{tabular}

$T P$ articles in the study period, $R(\%)$ the rank of total articles, $S P$ single-country articles, $C P$ internationally collaborated articles, $M C[P]$ major collaborator (the number of collaborated articles between two countries)

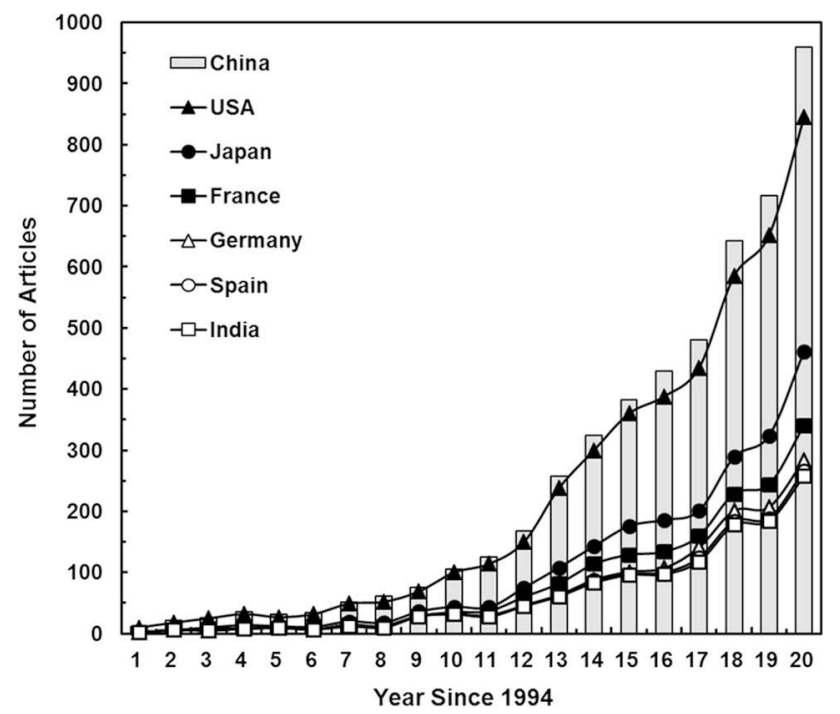

Fig. 5 The growth trends of the 7 most productive countries $(\mathrm{TP}>1200)$

1994. Moreover, China still had the highest growth rate and energy in recent years. The number of electrochemical technology for water and wastewater treatment articles in China slowly increased from 1994 to 2004 and rocketed during the period from 2005 to 2013 . With a similar develop trends, the numbers of ariticles in USA was also close to China. The other countries followed distantly and showed a similar increasing curve during the research period.

At the institution level, 26,296 articles from 8752 institutes in 118 countries, $12,327(46.9 \%)$ were inter-institutionally collaborative publications, and 13,969 $(53.1 \%)$ were independent publications. The percentage of collaboration between institutes was much higher than that between countries (28.9\%). Six institutes in China, four in Japan, two each in USA and France, and one each in Switzerland, Brazil, UK, India, Spain, and Russia, all of which were ranked in the top 20 most productive institutes as shown in Table 4.

It is worth noting that the Chinese Academy of Sciences with a highest h-index of 55 was the most productive institute for the total articles (796), as well as single institute articles (342), first authored articles (542), and corresponding authored articles (528), while the inter-institutionally collaborative articles (454) ranked 1st. There is a bias for the Chinese Academy of Sciences, as it has many branches in many cities. In this study, the articles of these institutes were regarded as one heading, dividing the articles into branches that would make difference in ranking (Fu et al. 2014). With the exception of Chinese Academy of Sciences, University of São Paulo, with 248 articles, 
Table 4 Top 20 most productive institutions of articles during 1994-2013

\begin{tabular}{|c|c|c|c|c|c|c|c|}
\hline \multirow[t]{2}{*}{ Institution } & \multirow[t]{2}{*}{$\mathrm{TP}$} & \multirow[t]{2}{*}{ TP $R(\%)$} & \multicolumn{2}{|c|}{$\begin{array}{l}\text { Single- } \\
\text { institution }\end{array}$} & \multicolumn{3}{|c|}{ Inner-institution collaborated } \\
\hline & & & SP & $\%$ & $\mathrm{CP}$ & $\%$ & $\mathrm{MC}[P]$ \\
\hline Chinese Acad Sci, China & 796 & $1(3.0)$ & 342 & 42.96 & 454 & $57.04(1)$ & Zhejiang Univ, China (22) \\
\hline Univ Sao Paulo, Brazil & 248 & $2(0.9)$ & 112 & 45.16 & 136 & $17.09(3)$ & Univ Fed ABC, Brazil (22) \\
\hline Russian Acad Sci, Russia & 248 & $2(0.9)$ & 112 & 45.16 & 136 & $17.09(4)$ & Moscow Mv Lomonosov State Univ, Russia (19) \\
\hline Penn State Univ, USA & 203 & $4(0.8)$ & 107 & 52.71 & 96 & $12.06(10)$ & Sandia Natl Labs, USA (11) \\
\hline Nanjing Univ, China & 198 & $5(0.8)$ & 102 & 51.52 & 96 & $12.06(11)$ & City Univ Hong Kong, China (8) \\
\hline Univ Paris 06, France & 175 & $6(0.7)$ & 43 & 24.57 & 132 & $16.58(5)$ & CNRS, France (19) \\
\hline CNRS, France & 175 & $6(0.7)$ & 27 & 15.43 & 148 & $18.59(2)$ & Univ Paris 06, France (19) \\
\hline Zhejiang Univ, China & 171 & $8(0.7)$ & 81 & 47.37 & 90 & $11.31(14)$ & Chinese Acad Sci, China (22) \\
\hline Wuhan Univ, China & 169 & $9(0.6)$ & 72 & 42.60 & 97 & $12.19(9)$ & Chinese Acad Sci, China (17) \\
\hline Univ Oxford, UK & 164 & $10(0.6)$ & 55 & 33.54 & 109 & $13.69(7)$ & Queens Univ Belfast, UK (20) \\
\hline Univ Barcelona, Spain & 162 & $11(0.6)$ & 59 & 36.42 & 103 & $12.94(8)$ & Univ Autonoma Barcelona, Spain (8) \\
\hline Tokyo Inst Technol, Japan & 160 & $12(0.6)$ & 86 & 53.75 & 74 & $9.3(18)$ & Tokyo Inst Technol, Japan (9) \\
\hline Univ Tokyo, Japan & 156 & $13(0.6)$ & 42 & 26.92 & 114 & $14.32(6)$ & Univ Tokyo, Japan (9) \\
\hline Indian Inst Technol, India & 148 & $14(0.6)$ & 87 & 58.78 & 61 & $7.66(19)$ & Bhabha Atom Res Ctr, India (7) \\
\hline Ecole Polytech Fed Lausanne, Switzerland & 141 & $15(0.5)$ & 48 & 34.04 & 93 & $11.68(12)$ & Univ Lausanne, Switzerland (10) \\
\hline Univ Calif Berkeley, USA & 136 & $16(0.5)$ & 59 & 43.38 & 77 & $9.67(16)$ & Caltech, USA (5) \\
\hline Dalian Univ Technol, China & 135 & $17(0.5)$ & 58 & 42.96 & 77 & $9.67(17)$ & Hong Kong Univ Sci and Technol, China (9) \\
\hline Tohoku Univ, Japan & 132 & $18(0.5)$ & 41 & 31.06 & 91 & $11.43(13)$ & Hitachi Ltd, Japan (11) \\
\hline Kyoto Univ, Japan & 122 & $19(0.5)$ & 67 & 54.92 & 55 & $6.91(20)$ & Ryukoku Univ, Japan (5) \\
\hline Tsinghua Univ, China & 121 & $20(0.5)$ & 41 & 33.88 & 80 & 10.05 & Chinese Acad Sci, China (9) \\
\hline
\end{tabular}

$T P$ articles in the study period, $R(\%)$ the rank of total articles, $S P$ Single-institution articles, $C P$ Inner-institution collaborated articles, $M C$ $[P]$ major collaborator (the number of collaborated articles between two institutions)

Russian Academy of Sciences, with 248 articles, and Pennsylvania State University, with 203 articles, ranked 2nd, 2nd, and 4th, with which the outputs of these three institutes were all above 200. The CNRS, France ranked 6th in the most productive institutes, whereas, ranked 2nd in the number of inter-institutionally collaborated articles. In addition, 6 of the top 20 most productive institutions were from China, the other 14 institutions were scattered in nine countries. $58.7 \%$ of articles produced by the 20 most productive institutions in electrochemical technology for water and wastewater treatment articles were inter-institutionally collaborated. It is obvious that institutions from the same country tended to have higher rates of collaboration, and the major collaborative institutions of these 20 institutions were all from the same country.

It is apparent that collaboration plays an ever-growing important role in electrochemical technology for water and wastewater treatment articles. Among the 26,296 articles with address information, 13,969 (53.1\%) were independent articles published by single institution, and the other articles were inter-institutional collaborative works, including both national $(28.9 \%)$ and international $(18.0 \%)$ collaborations. As seen in Fig. 6, the number of collaborative articles exceeded the number of independent

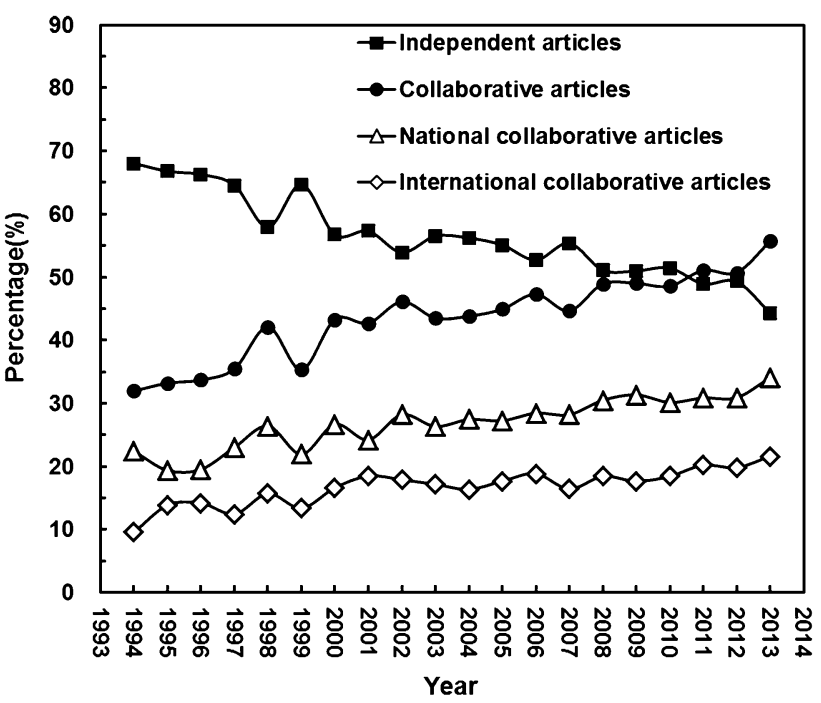

Fig. 6 Independent and collaborative share of articles per year during the research period

articles in 2011 and ultimately accounted for $55.7 \%$ of the total articles in 2013. In general, the increasing trend of collaborative articles relative to the total can be partly explained by the fact that the number of institutes and 
countries engaged in the electrochemical technology for water and wastewater treatment research increased. In collaborative articles, national articles consistently dominated, with an overall average of $61.7 \%$ over the 20 years. The proportion of international articles has recently gradually increased, from $32 \%$ in 1994 to $55.7 \%$ in 2013. We can anticipate that international collaboration will become the major form of collaborative articles in the future.

\section{Research tendency and hotspot}

\section{Author keywords}

The technique of statistical analysis of author keywords, articles title, article abstract, and keyword plus could be used to identify directions in science, and has proved to be efficient in comprehending and grasping the progress of new frontiers of science. Nowadays, bibliometric analysis of author keywords in different periods was further applied to analyze research trends (Chiu and Ho 2007; Xie et al. 2008), whereas using author keywords was much more infrequent (Imbelloni 2012). Excluding 8661 articles without author keywords information on the ISI Web of Science, the other 17,669 articles with author keywords information were analyzed. There were 5764 keywords listed by authors, however, 24,417 (74.18\%) keywords were used only once, 3690 (11.30\%) keywords were used twice, and the large number of once-only author keywords most likely indicated a lack of continuity in research and a wide disparity in research focuses (Chuang et al. 2007). Only 1078 $(3.3 \%)$ keywords were used more than ten times, which showed that the mainstream research in electrochemical technology for water and wastewater treatment was considered to focus on a small field. Keyword ranking changes in the four 5-year intervals are indicative of changes in the hot fields. The top 30 most frequently used keywords for the study period are listed in Table 5 .

With the exception of most frequently used author keyword "electrochemistry", which were search words in this study, the three most frequently used keywords were "Electrochemical Impedance Spectroscopy (EIS)" (718; $4.1 \%)$, "Cyclic Voltammetry" (599; $3.4 \%)$, "Corrosion" $(543 ; 3.1 \%)$. "Proton Exchange Membrane Fuel Cells (PEMFC)" received increased attention with a rise in rankings from 421 to 7 over the 20 years. In addition, "ionic liquid(s)" and "carbon nanotube(s)" might be new hot topics in the future since both of them did not appear in 1994-1998, but ranked 6th and 8th in 2009-2013, respectively. Ionic liquid(s), which could supply a suitable and stable environment, which draw a great attention on electrode modification (Wadhawan et al. 2000; Rozniecka et al. 2005), electrolyte solutions (Markevich et al. 2006; de Souza et al. 2007), and extraction of solvent and metal ions (Wei et al. 2003; Khachatryan et al. 2005). In previous researches (Munoz-Sandoval 2014), carbon nanotube(s) related literatures had increased enormously and represented a very important material in nanotechnology and nanoscience area.

Most of the top 30 author keywords were related to the following methods: electrochemical oxidation (electrochemical oxidation, electrolysis, electrooxidation, and oxidation) (1014; $5.8 \%)$, oxidants [hydrogen peroxide and hydroxyl radical(s)] (326; $1.8 \%)$, wastewater treatment (wastewater treatment and wastewater) (379; $2.1 \%)$, which are also the most important topics in electrochemical technology for water and wastewater treatment related research. Especially in the contemporary, electrochemical technology, which had promising potential to be developed as a robust, cost-effective and environmental friendly alternative, was universally applied to water and wastewater treatment. Electrocoagulation, electrodeposition, electrooxidation, electrodisinfection, electrofenton, electroflotation, and electrosorption were frequently found in electrochemical technologies. However, during the research, trends on electrochemical technology for water and wastewater treatment, electrocoagulation, electrodeposition and electrooxidation, which were ranked in the top 11 frequently used substantives in author keywords, were the three main electrochemical technologies. Both "electrocoagulation" (247; $1.4 \%)$ and "electrodeposition" (247; $1.4 \%$ ) had an apparent upward movement in their ranks, from 186 and 80 in 1994-1998 to 9 and 11 in 2009-2013. Electrocoagulation of wastewater using aluminum (Mouedhen et al. 2008; Heidmann and Calmano 2008a), iron (Heidmann and Calmano 2008b) or the hybrid $\mathrm{Al} / \mathrm{Fe}$ electrodes (Kobya et al. 2003; Gomes et al. 2007) has been reported by a number of authors. Electrodeposition was not only applied to the removal (Al-Shammari et al. 2004) and recycle (Szpyrkowicz et al. 2000) of heavy metal ions from wastewater, but also improved the performance of electrode by cathodic deposition (Habazaki et al. 2002). Electrooxidation, which was extensively investigated since the late 1970s (Mayeda et al. 1972; Nilsson et al. 1973), was quickly put into application of industrial wastewater (PiyaAreetham et al. 2006; Andrade et al. 2007; Zhu et al. 2009) and refractory organic matters (Rodrigo et al. 2001; Jiang et al. 2010; Choi et al. 2010) treatment.

\section{Articles title and articles abstract}

The titles containing the information of viewpoint and thought in articles were clearly expressed in front of readers (Baskerville 1904). In addition, the title, which provided a reasonably detailed picture of an article's theme, could draw great attention and called research 
Table 5 Top 30 frequently used substantives in author keywords during 1994-2013 and four 5-year periods

\begin{tabular}{|c|c|c|c|c|c|c|}
\hline Author keywords & 94-13 ТP & $94-13 R(\%)$ & $94-98 R(\%)$ & $99-03 R(\%)$ & 04-08 R (\%) & $09-13 R(\%)$ \\
\hline Electrochemistry & 955 & $1(5.4)$ & $1(6.3)$ & $1(5.5)$ & $1(5.3)$ & $1(5.3)$ \\
\hline Electrochemical Impedance Spectroscopy (EIS) & 718 & $2(4.1)$ & $4(3.0)$ & $3(3.5)$ & $2(3.7)$ & $2(4.6)$ \\
\hline Cyclic voltammetry & 599 & $3(3.4)$ & $2(4.1)$ & $2(4.3)$ & $3(3.6)$ & $4(2.9)$ \\
\hline Corrosion & 543 & $4(3.1)$ & $3(3.1)$ & $4(3.2)$ & $4(3.0)$ & $3(3.1)$ \\
\hline Electrochemical oxidation & 422 & $5(2.4)$ & $24(1.0)$ & $7(2.1)$ & $5(2.4)$ & $5(2.7)$ \\
\hline Electrocatalysis & 360 & $6(2.0)$ & $6(2.5)$ & $5(2.4)$ & $7(2.2)$ & $9(1.8)$ \\
\hline Proton exchange membrane fuel cells (PEMFC) & 331 & $7(1.9)$ & $421(0.1)$ & $50(0.6)$ & $6(2.3)$ & $7(2.0)$ \\
\hline Voltammetry & 325 & $8(1.8)$ & $6(2.5)$ & $5(2.4)$ & $8(1.8)$ & 12 (1.6) \\
\hline Copper & 260 & $9(1.5)$ & $5(2.9)$ & $11(1.3)$ & $13(1.3)$ & $15(1.4)$ \\
\hline Fuel cell(s) & 255 & $10(1.4)$ & $80(0.5)$ & $29(0.8)$ & $9(1.8)$ & $13(1.6)$ \\
\hline Electrocoagulation & 247 & $11(1.4)$ & $186(0.3)$ & $62(0.5)$ & $11(1.4)$ & $9(1.8)$ \\
\hline Electrodeposition & 247 & $11(1.4)$ & $80(0.5)$ & $12(1.2)$ & $13(1.3)$ & $11(1.6)$ \\
\hline Ionic liquid(s) & 239 & $13(1.4)$ & NA & $184(0.3)$ & $10(1.5)$ & $6(2.1)$ \\
\hline Carbon nanotube(s) & 232 & $14(1.3)$ & NA & $242(0.2)$ & $23(1.1)$ & $8(2.0)$ \\
\hline Adsorption & 224 & $15(1.3)$ & $8(2.3)$ & $12(1.2)$ & $19(1.2)$ & $23(1.2)$ \\
\hline Wastewater treatment & 220 & $16(1.2)$ & $142(0.3)$ & $8(1.5)$ & $16(1.3)$ & $16(1.3)$ \\
\hline Electrolysis & 219 & $17(1.2)$ & $67(0.6)$ & $9(1.4)$ & $11(1.4)$ & $19(1.2)$ \\
\hline Biosensor(s) & 218 & $18(1.2)$ & $20(1.0)$ & $20(1.0)$ & $20(1.1)$ & $14(1.4)$ \\
\hline Phenol(s) & 217 & $19(1.2)$ & $13(1.2)$ & $9(1.4)$ & $15(1.3)$ & $23(1.2)$ \\
\hline Titanium dioxide $\left(\mathrm{TiO}_{2}\right)$ & 188 & $20(1.1)$ & $13(1.2)$ & $38(0.7)$ & $17(1.2)$ & $26(1.0)$ \\
\hline Electrooxidation & 187 & $21(1.1)$ & $54(0.6)$ & $34(0.8)$ & $20(1.1)$ & $18(1.3)$ \\
\hline Oxidation & 186 & $22(1.1)$ & $24(1.0)$ & $19(1)$ & $33(0.9)$ & $21(1.2)$ \\
\hline Electrochemical & 183 & $23(1.0)$ & $80(0.5)$ & $29(0.8)$ & $20(1.1)$ & $25(1.1)$ \\
\hline Hydrogen peroxide & 167 & $24(0.9)$ & $24(1.0)$ & $16(1.2)$ & $17(1.2)$ & $51(0.7)$ \\
\hline Hydrogen & 165 & $25(0.9)$ & $80(0.5)$ & $24(0.9)$ & $31(0.9)$ & $28(1.0)$ \\
\hline Hydroxyl radical(s) & 159 & $26(0.9)$ & $80(0.5)$ & $25(0.9)$ & $26(1.0)$ & $32(0.9)$ \\
\hline Wastewater & 159 & $26(0.9)$ & $186(0.3)$ & $17(1.2)$ & $25(1.0)$ & $35(0.9)$ \\
\hline Electrochemical properties & 152 & $28(0.9)$ & $30(0.9)$ & $20(1)$ & $36(0.8)$ & $38(0.8)$ \\
\hline Stainless steel & 151 & $29(0.9)$ & $36(0.8)$ & $29(0.8)$ & $44(0.7)$ & $32(0.9)$ \\
\hline Polypyrrole & 148 & $30(0.8)$ & $13(1.2)$ & $29(0.8)$ & $26(1.0)$ & $55(0.7)$ \\
\hline
\end{tabular}

$T P$ articles in the study period, $R(\%)$ the rank and percentage of the author keywords

enthusiasm of the readers. Recently, distribution of words in article titles of different periods was applied in sedimentrelated trend research in earth science (Niu et al. 2014) and methane trend research in anaerobic digestion (Wang et al. 2013). In this study, all single words within the title of articles were statistically analyzed. However, the meaning of the single words in titles which sometimes does not make sense were discarded, such as, "a/an", "for", "of”, "the", "study", and "research". Articles title ranking changes in the four 5-year intervals are indicative of changes in the hot fields. The top 30 most frequency substantives in articles title used for the study period are listed in Table 6.

The most frequency substantives used in article titles were "electrochemistry" and "water", however, which should be ascribed to these words included in search topics of this study. Excluding the above factors, "Electrode(s)" which was found in 3638 article titles still might be the hottest topics during the last twenty years. Both "carbon"
$(2075 ; 7.9 \%)$ and "cell(s)" (1846; $7.0 \%)$ related to electrode(s) had an apparent upward progress in their ranks, from 21st and 40th in 1994-1998 to 4th and 5th in 2009-2013. "Fuel", "application(s)", "oxide", "treatment", "modified", and "nanotube(s)" showed a continuous increasing trend in titles, while the terms "solution(s)" showed a decreasing trend. It is worth mentioning that "Nanotube(s)" had a notable promotion, the same with "carbon nanotube(s)" in author keywords, which did not appear in 1994-1998, but ranked 15th in 2009-2013.

Distribution of words in article abstracts of different periods could also be the information of research trend analysis (Zhang et al. 2010a; Fu et al. 2014). In the analysis of article abstracts in current study, the words in article abstracts showed that "electrochemical", "electrode(s)", "water", "film(s)", "oxidation", "solution", "current", "potential", "temperature", "surface", "corrosion", "carbon", "reaction", "reduction", "cell", "detection", 
Table 6 Top 30 frequency substantives in articles title during 1994-2013 and four 5-year periods

\begin{tabular}{|c|c|c|c|c|c|c|}
\hline Title keywords & $94-13 \mathrm{TP}$ & $94-13 R(\%)$ & $94-98 R(\%)$ & 99-03 R (\%) & $04-08 R(\%)$ & $09-13 R(\%)$ \\
\hline Electrochemical & 6927 & $1(26.3)$ & $1(29.2)$ & $1(28.8)$ & $1(26.1)$ & $1(24.9)$ \\
\hline Electrode(s) & 3638 & $2(13.8)$ & $3(12.1)$ & $3(12.6)$ & $2(13.4)$ & $2(14.9)$ \\
\hline Water & 3462 & $3(13.1)$ & $2(12.7)$ & $2(12.9)$ & $4(12.3)$ & $3(13.8)$ \\
\hline Carbon & 2075 & $4(7.9)$ & $21(3.3)$ & $13(4.7)$ & $6(7.0)$ & $4(10.5)$ \\
\hline Cell(s) & 1846 & $5(7.0)$ & $40(2.1)$ & $14(4.5)$ & $5(7.8)$ & $5(8.6)$ \\
\hline Film(s) & 1834 & $6(7.0)$ & $7(6.5)$ & $4(7.8)$ & $3(12.7)$ & $9(6.2)$ \\
\hline Determination & 1650 & $7(6.3)$ & $4(7.9)$ & $7(6.3)$ & $11(5.9)$ & $10(6.1)$ \\
\hline Corrosion & 1643 & $8(6.2)$ & $6(7.2)$ & $5(6.8)$ & $7(6.5)$ & $11(5.7)$ \\
\hline Oxidation & 1595 & $9(6.1)$ & $9(5.0)$ & $8(5.8)$ & $14(5.5)$ & $7(6.7)$ \\
\hline Synthesis & 1521 & $10(5.8)$ & $11(4.4)$ & $20(3.9)$ & $12(5.7)$ & $6(6.8)$ \\
\hline Solution(s) & 1485 & $11(5.6)$ & $5(7.7)$ & $6(6.7)$ & $13(5.5)$ & $16(4.9)$ \\
\hline Properties & 1473 & $12(5.6)$ & $8(5.2)$ & $9(5.2)$ & $8(6.2)$ & $12(5.5)$ \\
\hline Fuel & 1340 & $13(5.1)$ & $127(1.0)$ & $33(2.8)$ & $10(5.9)$ & $8(6.3)$ \\
\hline Membrane(s) & 1333 & $14(5.1)$ & $31(2.6)$ & $18(4.3)$ & $9(6.1)$ & $13(5.3)$ \\
\hline Surface(s) & 1248 & $15(4.7)$ & $13(4.3)$ & $10(5.1)$ & $16(5.1)$ & $18(4.5)$ \\
\hline Liquid(s) & 1203 & $16(4.6)$ & $13(4.3)$ & $11(4.9)$ & $15(5.2)$ & $23(4.2)$ \\
\hline Application(s) & 1161 & $17(4.4)$ & $26(3.1)$ & $23(3.6)$ & $18(4.1)$ & $14(5.1)$ \\
\hline Characterization & 1137 & $18(4.3)$ & $24(3.2)$ & $14(4.5)$ & $17(4.7)$ & $20(4.3)$ \\
\hline Detection & 1089 & $19(4.1)$ & $16(4.1)$ & $20(3.9)$ & $20(3.9)$ & $19(4.3)$ \\
\hline Acid & 1046 & $20(4.0)$ & $17(4.1)$ & $16(4.4)$ & $19(3.9)$ & $26(3.8)$ \\
\hline Hydrogen & 1001 & $21(3.8)$ & $24(3.2)$ & $26(3.3)$ & $22(3.6)$ & $21(4.2)$ \\
\hline $\operatorname{Ion}(s)$ & 998 & $22(3.8)$ & $11(4.4)$ & $17(4.4)$ & $23(3.5)$ & $28(3.6)$ \\
\hline Aqueous & 997 & $23(3.8)$ & $18(3.7)$ & $12(4.8)$ & $25(3.5)$ & $27(3.6)$ \\
\hline Oxide & 973 & $24(3.7)$ & $42(2.1)$ & $29(3.0)$ & $28(3.2)$ & $17(4.6)$ \\
\hline Reduction & 932 & $25(3.5)$ & $10(4.9)$ & $22(3.9)$ & $21(3.6)$ & $35(3.1)$ \\
\hline Electrolyte(s) & 898 & $26(3.4)$ & $22(3.3)$ & $24(3.5)$ & $24(3.5)$ & $30(3.4)$ \\
\hline Treatment & 870 & $27(3.3)$ & $49(2.0)$ & $34(2.8)$ & $27(3.2)$ & $25(3.8)$ \\
\hline Steel & 868 & $28(3.3)$ & $27(3.0)$ & $26(3.3)$ & $26(3.3)$ & $29(3.4)$ \\
\hline Modified & 840 & $29(3.2)$ & $68(1.5)$ & $39(2.4)$ & $38(2.6)$ & $22(4.2)$ \\
\hline Nanotube(s) & 792 & $30(3.0)$ & NA & $509(0.3)$ & $50(2.2)$ & $15(5.1)$ \\
\hline
\end{tabular}

$T P$ the number of articles in the study period, $\%$ the percentage of the source title

"process", "hydrogen", “acid", “oxygen", "cyclic", "properties", "aqueous", and "pH" appeared at least 4,000 times. In all, "electrode(s)" still might be one of most popular issue during the electrochemical technology for the wastewater treatment. This result was similar to the preceding analysis in articles title (Zhang et al. 2010a).

\section{'KeyWords Plus'}

'KeyWords Plus', which were different from the author keywords, articles title and articles abstract, were automatically generated by the SCI from an algorithm that extracts key words from all the titles referenced or cited in the documents (Garfield 1990). In recent years, 'KeyWords Plus' in different periods have been presented as information of research trends during previous literature (Xie et al. 2008; Fu et al. 2010; Wang et al. 2013; Fu et al. 2014). 'KeyWords Plus' ranking changes in the four 5-year intervals are indicative of changes in the hot fields. The top 30 most frequently used 'KeyWords Plus' for the study period are listed in Table 7.

The analysis of 'KeyWords Plus' shows that 25,173 'KeyWords Plus' were used in 26,330 articles. The top ten most frequently used 'KeyWords Plus' were "water (4436; $17.6 \%)$ ", "electrode(s) (2339; $9.3 \%)$ ", “oxidation (1923; $7.6 \%)$ ", "film(s) (1593; $6.3 \%)$ ", “performance (1230; $4.9 \%)$ ", "behavior $(1211 ; 4.8 \%)$ ", "surface(s) (1188; $4.7 \%)$ ", “aqueous-solution(s) (1092; $4.3 \%)$ ", “degradation $(1090 ; 4.3 \%)$ ", "system(s) (1006; $4 \%)$ ", respectively. Some new research areas could also be found. "Nanoparticles" was ranked 1990 in 1994-1998, while ranked 10th in 2009-2013. It is worth mentioning that the 
Table 7 Top 30 frequently used substantives in author "KeyWords Plus" during 1994-2013 and four 5-year periods

\begin{tabular}{|c|c|c|c|c|c|c|}
\hline Author Keyword Plus & 94-13 TP & 94-13R $(\%)$ & $94-98 R(\%)$ & 99-03 R (\%) & 04-08 R(\%) & $09-13 R(\%)$ \\
\hline Water & 4436 & $1(17.6)$ & $1(16.8)$ & $1(17.1)$ & $1(17.3)$ & $1(18.2)$ \\
\hline Electrode(s) & 2339 & $2(9.3)$ & $2(9.1)$ & $2(8.0)$ & $2(8.8)$ & $2(10.0)$ \\
\hline Oxidation & 1923 & $3(7.6)$ & $5(5.1)$ & $3(6.5)$ & $3(7.9)$ & $3(8.4)$ \\
\hline Film(s) & 1593 & $4(6.3)$ & $4(5.4)$ & $4(5.5)$ & $4(6.3)$ & $5(6.8)$ \\
\hline Performance & 1230 & $5(4.9)$ & $67(1.0)$ & $25(2.4)$ & $7(4.3)$ & $4(6.8)$ \\
\hline Behavior & 1211 & $6(4.8)$ & $10(4.0)$ & $5(4.9)$ & $5(5.2)$ & $11(4.7)$ \\
\hline Surface(s) & 1188 & $7(4.7)$ & $7(5.0)$ & $6(4.6)$ & $8(4.3)$ & $8(5.0)$ \\
\hline Aqueous-solution(s) & 1092 & $8(4.3)$ & $16(2.6)$ & $15(2.9)$ & $9(4.3)$ & $7(5.2)$ \\
\hline Degradation & 1090 & $9(4.3)$ & $52(1.1)$ & $17(2.6)$ & $6(4.4)$ & $6(5.5)$ \\
\hline System(s) & 1006 & $10(4)$ & $9(4.5)$ & $11(3.8)$ & $11(4.0)$ & $14(3.9)$ \\
\hline Waste-water treatment & 948 & $11(3.8)$ & $72(0.9)$ & $12(3.4)$ & $10(4.1)$ & $13(4.3)$ \\
\hline Adsorption & 945 & $12(3.8)$ & $8(4.8)$ & $7(4.2)$ & $13(3.4)$ & $16(3.6)$ \\
\hline Reduction & 923 & $13(3.7)$ & $11(3.9)$ & $10(3.8)$ & $15(3.2)$ & $15(3.8)$ \\
\hline Waste-water & 839 & $14(3.3)$ & $347(0.3)$ & $55(1.3)$ & $21(2.9)$ & $9(4.9)$ \\
\hline Electrochemistry & 830 & $15(3.3)$ & $3(6.1)$ & $8(3.9)$ & $17(3.1)$ & $22(2.6)$ \\
\hline Removal & 815 & $16(3.2)$ & $125(0.6)$ & $44(1.5)$ & $19(2.9)$ & $12(4.5)$ \\
\hline Acid & 804 & $17(3.2)$ & $24(2.0)$ & $23(2.4)$ & $12(3.5)$ & $17(3.5)$ \\
\hline Electrochemical detection & 802 & $18(3.2)$ & $5(5.1)$ & $9(3.8)$ & $14(3.4)$ & $26(2.5)$ \\
\hline Kinetics & 751 & $19(3.0)$ & $12(3.8)$ & $12(3.4)$ & $15(3.2)$ & $23(2.6)$ \\
\hline Mechanism & 713 & $20(2.8)$ & $13(3.7)$ & $14(3.0)$ & $19(2.9)$ & $24(2.5)$ \\
\hline Nanoparticles & 705 & $21(2.8)$ & $1990(0.04)$ & $543(0.2)$ & $35(1.8)$ & $10(4.7)$ \\
\hline Thin-Films & 645 & $22(2.6)$ & $44(1.4)$ & $30(1.9)$ & $27(2.3)$ & $18(3.2)$ \\
\hline Transport & 625 & $23(2.5)$ & $27(1.8)$ & $16(2.6)$ & $18(3.0)$ & $31(2.3)$ \\
\hline Electrochemical oxidation & 613 & $24(2.4)$ & $59(1.1)$ & $43(1.6)$ & $23(2.6)$ & $19(2.9)$ \\
\hline Spectroscopy & 577 & $25(2.3)$ & $14(3.4)$ & $20(2.5)$ & $25(2.3)$ & $35(2.0)$ \\
\hline Oxide(s) & 573 & $26(2.3)$ & $29(1.8)$ & $31(1.8)$ & $35(1.8)$ & $20(2.8)$ \\
\hline Anodic-oxidation & 571 & $27(2.3)$ & $75(0.9)$ & $22(2.5)$ & $22(2.7)$ & $33(2.2)$ \\
\hline Membrane(s) & 548 & $28(2.2)$ & $39(1.4)$ & $39(1.6)$ & $24(2.5)$ & $29(2.3)$ \\
\hline Sensor(s) & 548 & $28(2.2)$ & $84(0.9)$ & $37(1.7)$ & $32(2.0)$ & $21(2.7)$ \\
\hline $\operatorname{Ion}(s)$ & 537 & $30(2.1)$ & $17(2.5)$ & $24(2.4)$ & $31(2.0)$ & $34(2.0)$ \\
\hline
\end{tabular}

$T P$ articles in the study period, $R(\%)$ : the rank and percentage of the author "KeyWords Plus"

notable promotion of "Nanoparticles" was similar to "carbon nanotube(s)" in author keywords, and "Nanotube(s)" in articles title. China was the leading country in nanoscience and nanotechnology research and published more papers per year than USA since 2010 (The word used in the search was "nano*" under the "title" from 1997 to 2012) (Munoz-Sandoval 2014). Both "Waste-Water" (839; $3.3 \%)$ and "Removal" (815; $3.2 \%)$ had an apparent upward movement in their ranks, from $349 \mathrm{~h}$ and 125 th in 1994-1998 to 9th and 12th in 2009-2013.

However, "water and wastewater treatment", "electrooxidation or electrochemical oxidation", and "electrode(s) or titanium dioxide $\left(\mathrm{TIO}_{2}\right)$ " were present in words in the author keywords, articles title, and 'KeyWords Plus' list, which still might be identified as current electrochemical technology for water and wastewater treatment research hotspots. Some words "anodic-oxidation", "aqueous-solution(s)", "behavior", "degradation", "kinetics", "removal", "sensor(s)", "spectroscopy", "thinfilms", only appeared in the rank of the 'KeyWords Plus' list describing the article's contents with greater variety. The analysis of 'KeyWords Plus' was particularly useful for the analysis and delimitation of a scientific domain, which expanded and refined the perspective of scientific research field.

\section{Hot issues}

Based on comprehensive analysis of the distribution of author keywords, title, abstract, and 'KeyWords Plus', researchers could obtain few valuable clues of the potential research hotspots. Moreover, a new method named "word 
cluster analysis" (Mao et al. 2010), which combined the author keywords, article title, and 'KeyWords Plus', had been successfully applied to trace the hotspot of related research field in previous work (Tanaka and Ho 2011; Huang et al. 2012; Fu et al. 2013; Tan et al. 2014). Therefore, it could comprehensively and accurately identify the overview of the research hotspots through the refinement of synonymic single words and congeneric phrases. Research tendency on electrochemical technology for water and wastewater treatment were extracted and separated into two categories research methods including electrochemical impedance spectroscopy (EIS), Cyclic Voltammetry (CV), and Mass Spectrometry (MS), and research items including electrode(s) and corrosion. In the topic of research methods category, the EIS included the words "electrochemical impedance spectroscopy (EIS)", "electrochemical impedance spectroscopy" and "EIS", CV included the words "Cyclic Voltammetric", "Cyclic Voltammetric", and "Cyclic Voltammetric Technique", and the MS included the words "Electrochemical MassSpectrometry", "Mass-Spectrometry", "Mass Spectrometry", "Mass Spectrometry (MS)", "MS", and "the other MS-related Method". Accordingly, the topic electrode(s) included the words "electrode" and "electrode", and the topic corrosion included only the word "corrosion" on research items.

Growth trend of hotpot-related articles during the last 20 years is shown in Fig. 7. All research related had revealed an escalating trend along with the increase of the total publications. The investigation by word cluster

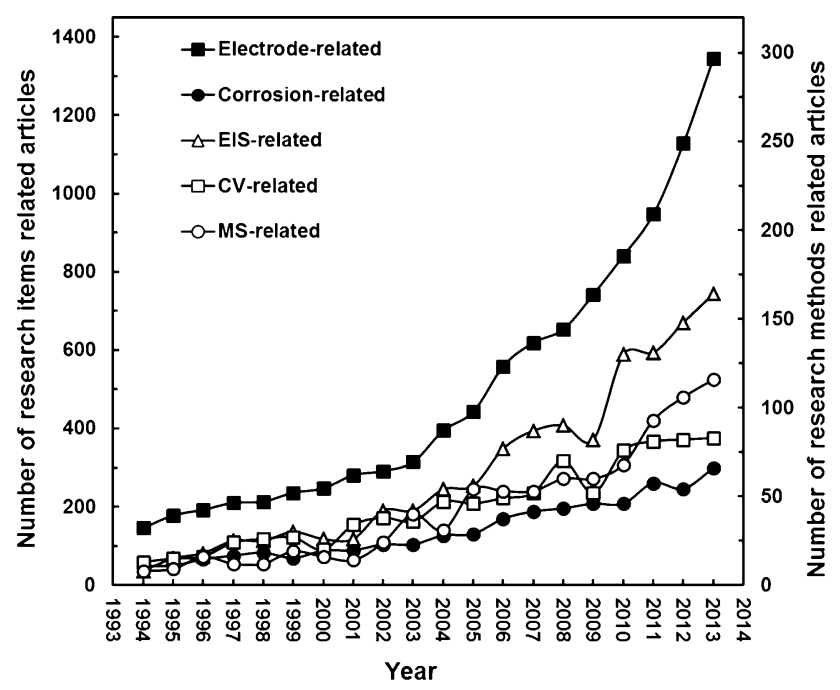

Fig. 7 Growth trend of hotpot-related articles during the last 20 years (note: research items related articles including electroderelated and corrosion-related articles, research methods related articles including EIS-related, CV-related and MS-related articles, solid symbols in main coordinates, and blank symbols in subcoordinates) analysis showed that EIS, CV, and MS could be the most commonly studied technique on electrochemical technology for water and wastewater treatment related research. EIS had attained tremendous increase in popularity and dominated the research methods since 2002, when EIS surpassed the research methods of CV and MS. Further, the EIS, which was a mature and well-known technique, had been widely used to analyze the characterization of electrode processes and corrosion performance. During the related researches on electrochemical technology for water and wastewater treatment, EIS mainly applied in the field of corrosion (Liu et al. 2003; Rios et al. 2013), coatings (Deflorian et al. 1994; Deflorian and Fedrizzi 1999), and fuel cells (Yi and Van Nguyen 1999; Lin and Van Nguyen 2005) since 1990s. In addition, EIS, which had been shown to be a powerful and useful tool in different scientific areas, was adopted to investigate the hotspot research on microbial fuel cells (MFCs) (He and Mansfeld 2009; Hosseini and Ahadzadeh 2012). Then, CV, which offered a first view on electrode/electrolyte systems in the potential window of interest, was the most commonly used method in electroanalysis and always combined with other analysis method (e.g., EIS, chronoamperometry, differential pulse voltammetry, square wave voltammetry, scanning electron microscope (SEM), MS and X-ray diffraction); Finally, MS measurements, which were carried out in the gas phase on ionized analytes, were generally applied to analyze the chemical and element. Nowadays, integrated with other techniques, MS had obtained technical and conceptual advances by liquid chromatography mass-spectrometry (LC-MS), gas chromatography mass-spectrometry (GCMS), electrospray ionization mass-spectrometry (ESI-MS), desorption/ionization mass-spectrometry, capillary electrophoresis-mass spectrometry, Fourier transform ion cyclotron resonance mass spectrometry, time-of-flight mass spectrometry, plasma-mass-spectrometry, trap mass-spectrometry, and differential electrochemical mass spectrometry. These techniques had their own strength and weakness because of the difference of design and performance. Moreover, these analysers could separately analyze specific analysis or put together in tandem to overcome the weakness of each. In addition, it is worth mentioning that the role of MS-based proteomics had been successfully illustrated as an indispensable tool for molecular and cellular biology (Aebersold and Mann 2003). The related result indicated that the ability of mass spectrometry to precisely identify and quantify complex molecular chemicals could be expected to impact broadly on different scientific areas.

As shown in Fig. 7, the amount of the research items on corrosion continuously increased from 1994 to 2013, but decreased a little bit in 2012. "Corrosion" was one of the most important research directions on electrochemical 
technology for water and wastewater treatment, which were mainly focused on pitting corrosion, localized corrosion, atmospheric corrosion, corrosion protection, corrosion resistance, and corrosion inhibition. Pitting corrosion (Frankel 1998) which belonged to localized corrosion accelerated the dissolution of metal when the otherwise protective passive film on metal surface was broken down. Moreover, researchers had paid more concern on the effects of alloy composition (Williams et al. 2010), environment (Jafarian et al. 2008), potential (Lee et al. 2011), and temperature (Lee et al. 2010). Atmospheric corrosion which was a new scientific focus on the corrosion process had been studied by engineers for nearly a century. Leygraf and Graedel (2000) firstly comprehensively described the corrosion on structures and materials, and properly used latest scientific tools to prevent or minimize the corrosion damage. Therefore, corrosion protection, corrosion resistance, and corrosion inhibition had appeared in anticorrosion field for the prevention of different metals and alloys, which was achieved by specific coatings or composite films on their surface. Besides, nano-structured surface treatment coatings was widely used in the manufacture of the specific coatings or composite films, such as, tantalum oxide nanoparticle coatings (Shen et al. 2005; Díaz et al. 2013), nano-siloxane epoxy coating (Bagherzadeh et al. 2012), and nano-structured polymeric coatings (Aglan et al. 2007). In addition, novel area of corrosion mainly focused on copper corrosion, microbiological corrosion, and $\mathrm{CO}_{2}$ corrosion in recent years.

Compared with the well growth trend of corrosion, the amount of the research items on electrode(s) fluctuated from 1994 to 2003 and significantly rocketed since 2008, which revealed that the electrode-related research was the hotspot on electrochemical technology for water and wastewater treatment. Recently, researchers (Chen 2004; Anglada et al. 2009; Wang et al. 2010; Sun et al. 2012b) had paid great attention on the removal efficiency in degrading various pollutants on all kinds of electrodes, enhancement of electrochemical stability of anodic material of electrodes, investigation of factors affecting the electrodes performance, and explanation of the mechanisms and kinetics of pollutant degradation. During the anodic materials of common electrode, such as, graphite, carbon fibers, platinum, diamond, gold $(\mathrm{Au})$, aluminum, iron, $\mathrm{PbO}_{2}, \mathrm{SnO}_{2}, \mathrm{TiO}_{2}, \mathrm{Ti} / \mathrm{Pt}, \mathrm{Ti} / \mathrm{SnO}_{2}, \mathrm{Ti} / \mathrm{PbO}_{2}, \mathrm{Ti} / \mathrm{RuO}_{2}-$ $\mathrm{TiO}_{2}, \mathrm{Ti} / \mathrm{IrO}_{2}-\mathrm{TiO}_{2}, \quad \mathrm{Ti} / \mathrm{IrO}_{2}-\mathrm{RuO}_{2}-\mathrm{TiO}_{2}$, boron-doped diamond (BDD) electrode, Titanium-based boron-doped diamond electrode (BDD/Ti) were widely used in the wastewater treatment. Among them, graphite, platinum, and the dimensionally stable anodes (DSA ${ }^{\circledR}$ ) was identified as the most common insoluble anodes, whereas, revealed a lower oxygen evolution overpotential and durability;
Aluminum and iron was usually applied in electrocoagulation, which were effective on the treatment of water and wastewater, respectively. However, $\mathrm{PbO}_{2}, \mathrm{SnO}_{2}, \mathrm{TiO}_{2}$ and diamond electrode seemed to be the potential anode materials with high oxygen evolution overpotentials. Moreover, $\mathrm{PbO}_{2}$ electrode are relatively cheap and widely used in oxidizing pollutants, but there was some concern for its toxic $\mathrm{Pb}^{2+}$ ions; $\mathrm{SnO}_{2}$ was always not effective because of its poor electrochemical stability; $\mathrm{TiO}_{2}$, combined with ultraviolet technique, was usually used as a photocatalyst in wastewater treatment; Diamond electrode was well known for its high strength, strong hardness, and long durability and usually served as anodic substrates with other metal materials. Nowadays, Titanium or other noble metal-based electrodes including $\mathrm{Ti} / \mathrm{RuO}_{2}-\mathrm{TiO}_{2}, \mathrm{Ti} / \mathrm{IrO}_{2}$ $\mathrm{TiO}_{2}, \mathrm{Ti} / \mathrm{IrO}_{2}-\mathrm{RuO}_{2}-\mathrm{TiO}_{2}$ showed high oxygen evolution overpotential and well electrochemical performance, which would be the promising anode materials in industrial application. In addition, BDD/Ti electrode with high oxygen evolution overpotential (Chen et al. 2003), which was a new frontier of electrode application, was found to be the most active anodic material for degradation of refractory pollutants. Therefore, the hotspots on electrochemical technology for water and wastewater treatment related research was novel electrode, which owned high oxygen evolution overpotential and good physiochemical and electrochemical properties.

\section{Conclusions}

Based on 26,330 electrochemical technologies for water and wastewater treatment related publications dealing with SCI, this bibliometric study provided an overview of research in electrochemical technology for water and wastewater treatment and identified some significant points in the research throughout the investigation period. Electrochemical technology for water and wastewater treatment related researches have significantly increased in the last 20 years. A power model and an exponential model were applied to illustrate the relations between cumulative number of articles and the year. Furthermore, based on the exponential model, it can be calculated that the number of articles in 2018 will be twice than that in 2013. Articles were published in 1790 journals in 106 subject categories. Journal of the Electrochemical Society with a top h-index of 90 published the most articles in this field, taking $5.8 \%$ of all, followed by Electrochimica Acta and Journal of Electroanalytical Chemistry. The researchers focused on categories of chemistry, electrochemistry, and materials science. China and Chinese Academy of Sciences were the most productive country and institution, respectively, while USA, with the most international collaborative articles and 
highest h-index of 130, was the major collaborator with other 15 countries in top 20 most productive countries. The G7 and BRIC accounted for 40.7 and $23.2 \%$ of the total world production. Word cluster analysis was successfully used to trace the hotspot on electrochemical technology for water and wastewater treatment related research, which showed that the novel anodic electrode with high oxygen evolution overpotential and good physiochemical and electrochemical properties was the hotspot.

Acknowledgments The authors gratefully acknowledge the financial support of the Major Science and Technology Program for Water Pollution Control and Treatment (2012ZX07201002-6).

Open Access This article is distributed under the terms of the Creative Commons Attribution License which permits any use, distribution, and reproduction in any medium, provided the original author(s) and the source are credited.

\section{References}

Aebersold R, Mann M (2003) Mass spectrometry-based proteomics. Nature 6928:198-207

Afzal A, Pourrezaei P, Ding N et al (2011) Physico-Chemical Processes. Water Environ Res 10:994-1091

Aglan A, Allie A, Ludwick A et al (2007) Formulation and evaluation of nano-structured polymeric coatings for corrosion protection. Surf Coat Tech 2:370-378

Al-Shammari AA, Rahman SU, Chin D (2004) An oblique rotating barrel electrochemical reactor for removal of copper ions from wastewater. J Appl Electrochem 4:447-453

Andrade LS, Ruotolo LAM, Rocha-Filho RC et al (2007) On the performance of $\mathrm{Fe}$ and $\mathrm{Fe}, \mathrm{F}$ doped $\mathrm{Ti}-\mathrm{Pt} / \mathrm{PbO}_{2}$ electrodes in the electrooxidation of the Blue Reactive 19 dye in simulated textile wastewater. Chemosphere 11:2035-2043

Anglada A, Urtiaga A, Ortiz I (2009) Contributions of electrochemical oxidation to waste-water treatment: fundamentals and review of applications. J Chem Technol Biot 12:1747-1755

Bagherzadeh MR, Daneshvar A, Shariatpanahi H (2012) Novel waterbased nanosiloxane epoxy coating for corrosion protection of carbon steel. Surf Coat Tech 8:2057-2063

Baskerville C (1904) The Titles of Papers. Science (New York, NY) 487:702-703

Canizares P, Hernandez M, Rodrigo MA et al (2008) Electrooxidation of brown-colored molasses wastewater. Effect of the electrolyte salt on the process efficiency. Ind Eng Chem Res 3:1298-1301

Chang M, Gao C, Jiang J (2009) Electrochemical oxidation of organic compounds using boron-doped diamond electrode. J Electrochem Soc 2:E50-E54

Chen G (2004) Electrochemical technologies in wastewater treatment. Sep Purif Technol 1:11-41

Chen X, Chen G, Yue PL (2002) Novel electrode system for electroflotation of wastewater. Environ Sci Technol 4:778-783

Chen X, Chen G, Yue PL (2003) Anodic oxidation of dyes at novel Ti/B-diamond electrodes. Chem Eng Sci 3:995-1001

Chiu W, Ho Y (2007) Bibliometric analysis of tsunami research. Scientometrics 1:3-17

Choi JY, Lee Y, Shin J et al (2010) Anodic oxidation of 1,4-dioxane on boron-doped diamond electrodes for wastewater treatment. J Hazard Mater 1:762-768
Chuang K, Huang Y, Ho Y (2007) A bibliometric and citation analysis of stroke-related research in Taiwan. Scientometrics 2:201-212

Ciriminna R, Pagliaro M (2013) On the use of the h-index in evaluating chemical research. Chem Cent J 1:132

de Souza RF, Padilha JC, Gonçalves RS et al (2007) Electrochemical hydrogen production from water electrolysis using ionic liquid as electrolytes: towards the best device. J Power Sources 2:792-798

Deflorian F, Fedrizzi L (1999) Adhesion characterization of protective organic coatings by electrochemical impedance spectroscopy. J Adhes Sci Technol 5:629-645

Deflorian F, Miskovic-Stankovic VB, Bonora PL et al (1994) Degradation of epoxy coatings on phosphatized zinc-electroplated steel. Corrosion 6:438-446

Díaz B, Światowska J, Maurice V et al (2013) Tantalum oxide nanocoatings prepared by atomic layer and filtered cathodic arc deposition for corrosion protection of steel: Comparative surface and electrochemical analysis. Electrochim Acta 90:232-245

Feng C, Sugiura N, Shimada S et al (2003) Development of a high performance electrochemical wastewater treatment system. J Hazard Mater 1:65-78

Frankel GS (1998) Pitting corrosion of metals a review of the critical factors. J Electrochem Soc 6:2186-2198

Fu HZ, Ho YS, Sui YM et al (2010) A bibliometric analysis of solid waste research during the period 1993-2008. Waste Manage 12:2410-2417

Fu H, Wang M, Ho Y (2013) Mapping of drinking water research: a bibliometric analysis of research output during 1992-2011. Sci Total Environ 443:757-765

Fu HZ, Long X, Ho YS (2014) China's research in chemical engineering journals in Science Citation Index Expanded: a bibliometric analysis. Scientometrics 1:119-136

Gao Y, Tsuji H, Hattori H et al (1994) New on-line mass spectrometer system designed for platinum-single crystal electrode and electroreduction of acetylene. J Electroanal Chem 1:195-200

Garfield E (1990) Key-words-plus takes you beyond title words. 2. Expanded Journal Coverage for Current-Contents-on-Diskette Includes Social and Behavioral-Sciences. Current Contents 33:5-9

Ge J, Qu J, Lei P et al (2004) New bipolar electrocoagulationelectroflotation process for the treatment of laundry wastewater. Sep Purif Technol 1:33-39

Ghernaout D, Ghernaout B (2010) From chemical disinfection to electrodisinfection: the obligatory itinerary? Desalin Water Treat 1-3:156-175

Gomes JA, Daida P, Kesmez M et al (2007) Arsenic removal by electrocoagulation using combined $\mathrm{Al}-\mathrm{Fe}$ electrode system and characterization of products. J Hazard Mater 2:220-231

Grady CL Jr, Daigger GT, Love NG et al (2011) Biological wastewater treatment. IWA Publishing, UK

Habazaki H, Hayashi Y, Konno H (2002) Characterization of electrodeposited $\mathrm{WO}_{3}$ films and its application to electrochemical wastewater treatment. Electrochim Acta 26:4181-4188

He Z, Mansfeld F (2009) Exploring the use of electrochemical impedance spectroscopy (EIS) in microbial fuel cell studies. Energy Environ Sci 2:215-219

Heidmann I, Calmano W (2008a) Removal of Zn (II), Cu (II), Ni (II), $\mathrm{Ag}(\mathrm{I})$ and $\mathrm{Cr}(\mathrm{VI})$ present in aqueous solutions by aluminium electrocoagulation. J Hazard Mater 3:934-941

Heidmann I, Calmano W (2008b) Removal of Cr(VI) from model wastewaters by electrocoagulation with Fe electrodes. Sep Purif Technol 1:15-21

Hirsch JE (2005) An index to quantify an individual's scientific research output. P Natl Acad Sci USA 46:16569-16572

Hirsch JE (2007) Does the $h$ index have predictive power? Proc Natl Acad Sci 49:19193-19198 
Hosseini MG, Ahadzadeh I (2012) A dual-chambered microbial fuel cell with $\mathrm{Ti} /$ nano-TiO $<$ sub $>2 / \mathrm{Pd}$ nano-structure cathode. J Power Sources 292-297

Hu J, Ma YW, Zhang L et al (2010) A historical review and bibliometric analysis of research on lead in drinking water field from 1991 to 2007. Sci Total Environ 7:1738-1744

Huang C, Su Y (2010) Removal of copper ions from wastewater by adsorption/electrosorption on modified activated carbon cloths. J Hazard Mater 1:477-483

Huang W, Zhang B, Feng C et al (2012) Research trends on nitrate removal: a bibliometric analysis. Desalin Water Treat 1-3:67-77

Imbelloni LE (2012) Scientific articles' titles: thanks for the information contained in your title. Revista brasileira de anestesiologia 2:140

Jafarian M, Gobal F, Danaee I et al (2008) Electrochemical studies of the pitting corrosion of tin in citric acid solution containing $\mathrm{Cl}^{-}$. Electrochim Acta 13:4528-4536

Jiang C, Zhang J (2007) Progress and prospect in electro-Fenton process for wastewater treatment. J Zhejiang Univ Sci A $7: 1118-1125$

Jiang Y, Zhu X, Li H et al (2010) Effect of nitro substituent on electrochemical oxidation of phenols at boron-doped diamond anodes. Chemosphere 9:1093-1099

Khachatryan KS, Smirnova SV, Torocheshnikova II et al (2005) Solvent extraction and extraction-voltammetric determination of phenols using room temperature ionic liquid. Anal Bioanal Chem 2:464-470

Kobya M, Can OT, Bayramoglu M (2003) Treatment of textile wastewaters by electrocoagulation using iron and aluminum electrodes. J Hazard Mater 1:163-178

Lee S, Kim J, Koo J (2010) Investigation of pitting corrosion of a copper tube in a heating system. Eng Fail Anal 6:1424-1435

Lee C, Batchelor B, Park SH et al (2011) Perchlorate reduction during electrochemically induced pitting corrosion of zero-valent titanium (ZVT). J Hazard Mater 197:183-189

Leygraf C, Graedel T (2000) Atmospheric corrosion. Wiley-Interscience, New york

Lin G, Van Nguyen T (2005) Effect of thickness and hydrophobic polymer content of the gas diffusion layer on electrode flooding level in a PEMFC. J Electrochem Soc 10:A1942-A1948

Liu C, Bi Q, Leyland A et al (2003) An electrochemical impedance spectroscopy study of the corrosion behaviour of PVD coated steels in $0.5 \mathrm{~N} \mathrm{NaCl}$ aqueous solution: part II: EIS interpretation of corrosion behaviour. Corros Sci 6:1257-1273

Mao N, Wang M, Ho Y (2010) A bibliometric study of the trend in articles related to risk assessment published in Science Citation Index. Hum Ecol Risk Assess 4:801-824

Markevich E, Baranchugov V, Aurbach D (2006) On the possibility of using ionic liquids as electrolyte solutions for rechargeable $5 \mathrm{~V}$ $\mathrm{Li}$ ion batteries. Electrochem Commun 8:1331-1334

Marselli B, Garcia-Gomez J, Michaud P et al (2003) Electrogeneration of hydroxyl radicals on boron-doped diamond electrodes. J Electrochem Soc 3:D79-D83

Martinez-Huitle CA, Ferro S (2006) Electrochemical oxidation of organic pollutants for the wastewater treatment: direct and indirect processes. Chem Soc Rev 12:1324-1340

Mayeda EA, Miller LL, Wolf JF (1972) Electrooxidation of benzylic ethers, esters, alcohols, and phenyl epoxides. J Am Chem Soc 19:6812-6816

Mouedhen G, Feki M, Wery M et al (2008) Behavior of aluminum electrodes in electrocoagulation process. J Hazard Mater 1:124-135

Munoz-Sandoval E (2014) Trends in nanoscience, nanotechnology, and carbon nanotubes: a bibliometric approach. J Nanopart Res $1: 1-22$
Nilsson A, Ronlán A, Parker VD (1973) Anodic oxidation of phenolic compounds. Part III. Anodic hydroxylation of phenols. A simple general synthesis of 4-alkyl-4-hydroxycyclo-hexa-2, 5-dienones from 4-alkylphenols. J. Chem. Soc. Perkin Trans 1:2337-2345

Niu BB, Hong S, Yuan JF et al (2014) Global trends in sedimentrelated research in earth science during 1992-2011: a bibliometric analysis. Scientometrics 1:511-529

Piya-Areetham P, Shenchunthichai K, Hunsom M (2006) Application of electrooxidation process for treating concentrated wastewater from distillery industry with a voluminous electrode. Water Res 15:2857-2864

Pritchard A (1969) Statistical bibliography or bibliometrics. J Doc 4:348-349

Rios JF, Calderón JA, Nogueira RP (2013) Electrochemical behavior of metals used in drinking water distribution systems: a rotating cylinder electrode's study. Corrosion 9:875-885

Rodrigo MA, Michaud PA, Duo I et al (2001) Oxidation of 4-chlorophenol at boron-doped diamond electrode for wastewater treatment. J Electrochem Soc 5:D60-D64

Rozniecka E, Shul G, Sirieix-Plenet J et al (2005) Electroactive ceramic carbon electrode modified with ionic liquid. Electrochem Commun 3:299-304

Shen GX, Chen YC, Lin CJ (2005) Corrosion protection of $316 \mathrm{~L}$ stainless steel by a $\mathrm{TiO}_{2}$ nanoparticle coating prepared by solgel method. Thin Solid Films 1:130-136

Sun J, Wang M, Ho Y (2012a) A historical review and bibliometric analysis of research on estuary pollution. Mar Pollut Bull 1:13-21

Sun Z, Wei X, Hu X et al (2012b) Electrocatalytic dechlorination of 2,4-dichlorophenol in aqueous solution on palladium loaded meshed titanium electrode modified with polymeric pyrrole and surfactant. Colloid Surface A 414:314-319

Szpyrkowicz L, Kaul SN, Molga E et al (2000) Comparison of the performance of a reactor equipped with a $\mathrm{Ti} / \mathrm{Pt}$ and an SS anode for simultaneous cyanide removal and copper recovery. Electrochim Acta 2:381-387

Tan J, Fu H, Ho Y (2014) A bibliometric analysis of research on proteomics in science citation index expanded. Scientometrics 2:1473-1490

Tanaka H, Ho Y (2011) Global trends and performances of desalination research. Desalin Water Treat 1-3:1-12

Trocónis De Rincón O, Sánchez M, Millano V et al (2007) Effect of the marine environment on reinforced concrete durability in Iberoamerican countries: DURACON project/CYTED. Corros Sci 7:2832-2843

Un UT, Altay U, Koparal AS et al (2008) Complete treatment of olive mill wastewaters by electrooxidation. Chem Eng J 3:445-452

Valero D, Ortiz JM, Expósito E et al (2010) Electrochemical wastewater treatment directly powered by photovoltaic panels: electrooxidation of a dye-containing wastewater. Environ Sci Technol 13:5182-5187

Wadhawan JD, Schröder U, Neudeck A et al (2000) Ionic liquid modified electrodes. Unusual partitioning and diffusion effects of $\mathrm{Fe}(\mathrm{CN})_{6}^{4-13-}$ in droplet and thin layer deposits of 1-methyl-3$(2,6-(<i>S)$-dimethylocten-2-yl)-imidazolium tetrafluoroborate. J Electroanal Chem 1:75-83

Wagner R, Preschitschek N, Passerini S et al (2013) Current research trends and prospects among the various materials and designs used in lithium-based batteries. J Appl Electrochem 5:481-496

Wang G, Gao Y, Wang Z et al (2010) Investigation of PtNi/C anode electrocatalysts for direct borohydride fuel cell. J Power Sour 1:185-189

Wang L, Wang Q, Zhang X et al (2013) A bibliometric analysis of anaerobic digestion for methane research during the period 1994-2011. J Mater Cycles Waste Manage 1:1-8 
Wei G, Yang Z, Chen C (2003) Room temperature ionic liquid as a novel medium for liquid/liquid extraction of metal ions. Anal Chim Acta 2:183-192

Williams DE, Kilburn MR, Cliff J et al (2010) Composition changes around sulphide inclusions in stainless steels, and implications for the initiation of pitting corrosion. Corros Sci 11:3702-3716

Xie SD, Zhang J, Ho YS (2008) Assessment of world aerosol research trends by bibliometric analysis. Scientometrics 1:113-130

Yi JS, Van Nguyen T (1999) Multicomponent transport in porous electrodes of proton exchange membrane fuel cells using the interdigitated gas distributors. J Electrochem Soc 1:38-45
Zhang GF, Xie SD, Ho YS (2010a) A bibliometric analysis of world volatile organic compounds research trends. Scientometrics 2:477-492

Zhang LA, Wang MH, Hu J et al (2010b) A review of published wetland research, 1991-2008: ecological engineering and ecosystem restoration. Ecol Eng 8:973-980

Zhu X, Ni J, Lai P (2009) Advanced treatment of biologically pretreated coking wastewater by electrochemical oxidation using boron-doped diamond electrodes. Water Res 17:4347-4355 